\title{
EFFICACY COMPARISON BETWEen ANTI-MALARIAL DRUgS IN AfRICANS PRESENTING WITH MILD MALARIA IN THE CeNTRAL RepUbliC OF Africa: A PRELIMINARY STUdY
}

\author{
NAMBEI W.S.*, GBAGBA F.E.**, NDÉMANGA J.***, DOUI-DOUMGBA K.***, DIALLO T.O.****, \\ NDADJIMBAYE V.*****, FLORI P.*******, PERRAUT R.******* \& GARRAUD O.*******
}

Summary:

Drug resistance to Plasmodium falciparum contributes to major health problems in central Africa and, as a consequence, poverty. We have analyzed the efficacy of three currently available antimalarial drugs to treat symptomatic, uncomplicated $P$. falciparum malaria in semiimmune adults living in Bangui, Central Republic of Africa. 210 consecutive individuals were enrolled in the survey, of which 45 were excluded. Those having received dihydroartemisin proved significantly less parasitemic than those having received quinine per os or sulfadoxin-pyrimethamin $\left(\chi^{2}=16.93 ; p<0.05\right)$, and $75 \%$ recovered in two days compared to 57 and $44 \%$, respectively. The $25 \%$ who did not recover benefited from a second cure with dihydroartemisin, which proved $100 \%$ efficient. The most accurate protocol remains to be established by analyzing clinical and parasitological data and taking into account the economics of the country.

KEY WORDS : malaria, drug, Africa, dihydroartemisin, Artecom ${ }^{\circledR}$, piperaquine.
Résumé : COMPARAISON ENTRE DIFFÉRENTS TRAITEMENTS ANTI-PALUDÉENS (ACCÈs SIMPLE) EN RÉPUBlique CENTRAFRICAINE : ÉTUde PRÉLIMINAIRE

La résistance de Plasmodium falciparum aux traitements est à l'origine de problèmes de santé majeurs en Afrique Centrale, qui ont pour conséquence la pauvreté. Nous avons analysé l'efficacité de trois médicaments disponibles actuellement afin de traiter le paludisme symptomatique, mais non compliqué, chez des adultes partiellement immunisés vivant à Bangui (RCA). 210 individus différents ont pris part à cette étude. Ceux qui avaient reçu de la dihydroartémisine ont été significativement moins parasitémiques que ceux ayant reçu de la quinine orale ou de la sulfadoxine-pyriméthamine : et $75 \%$ des patients ont guéri en deux jours vs $57 \%$ et $44 \%$ respectivement. Les $25 \%$ qui n'ont pas guéri ont reçu un deuxième traitement de dihydroartémisine qui s'est révélé efficace à $100 \%$. Un protocole adapté doit être mis au point en analysant des données cliniques et parasitologiques, et en tenant compte de l'économie du pays.

MOTS CLÉS : paludisme, traitement, Afrique, dihydroartémisine, Artecom ${ }^{\circledR}$, pipéraquine.
$\mathrm{M}$ alaria is still a major health-threatening problem in sub-Saharan Africa and increasing resistance to anti-malarial drugs, along with the occurrence of multiple concurrent infections, seriously complicates this situation (Bentwich et al., 2000). Several anti-malarial drugs were commonly used in Central Africa such as sulfadoxin-pyrimethamin, chloroquine and quinine. More recently, dihydroartemisin was included as a novel anti-malarial drug to treat uncomplicated malaria (White \& Oliaro, 1998).

\footnotetext{
* Service de Pharmacie, ** Service des Urgences Médicales,

***** Laboratoire d'Analyses Médicales, Hôpital Communautaire de Bangui, Bangui, Central African Republic.

*** Service des Urgences Médico-Chirurgicales, Hôpital Amitié de Bangui, Bangui, Central African Republic.

****** Centre d'Immunologie et de Biologie Parasitaire, Institut Pasteur de Lille, Lille, France.

******* GIMAP-EA 3064, Faculté de Médecine, Université Jean Monnet, Saint-Étienne, France.

*****:*** Laboratoire d'Immunologie, Institut Pasteur de Dakar, Sénégal. Correspondence : Dr Wilfrid S. Nambei, Hôpital Communautaire de Bangui, BP 1306, Bangui, CRA. Tel.: 236509075 - E-mail nambei@caramail.com

or Pr Olivier Garraud, Faculté de Médecine, 15 rue Ambroise Paré, 42023 Saint-Étienne cedex 03, France. Tel.: 33477814255 E-mail : olivier.garraud@univ-st-etienne.fr
}

Artecom ${ }^{\circledR}$ has received recent and strengthened interest as it proved efficacy against multidrug resistant P. falciparum malaria in several parts of the world (Tran et al., 2004). For instance, the dihydroartemisin component used consists of a composed molecule termed Artecom $^{\circledR}$. Relapse (resistance of parasites) and concurrent re-infection with novel parasite allelic variants are the major events affecting the efficacy of antimalarial treatment (Djimbe et al., 2003).

The present investigation aimed at evaluating several drug regimens that can be used both in terms of efficacy and of availability and economics, to treat uncomplicated malaria in a holo-endemic malaria area corresponding to a very low-income country (actually amongst the poorest). The study was performed in Bangui, Central Republic of Africa (CRA). The drug efficacy readout was the respective \% of consolidated recovery and relapses.

\section{PATIENTS AND SURVEY}

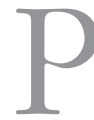
atients enrolled in the present survey were comprised of a homogeneous population of male and female Africans residing in Bangui (ratio: 
0.7) aged 18 to 32. As Bangui is a holo-endemic area, patients (i.e. adults) were likely to be in the process of acquiring some degree of immunity to Plasmodium falciparum (the most prevalent species of Plasmodium ssp in the CRA). A study was conducted at the Hôpital Communautaire de Bangui (HCB) to evaluate treatment protocols to cure non-complicated (mild) malaria in adults; those treatments are expected to be (1) safe; (2) as cheap as possible; and (3) suitable in a poor income country with some degree of political instability. The inclusion period was from May $2^{\text {nd }}$ to June $30^{\text {th }}, 2001$, and the survey period was from May $2^{\text {nd }}$ to July $14^{\text {th }}$. This period immediately follows the rainy season and spans the annual peak of malaria transmission.

A total number of 210 individuals were enrolled consecutively at the time of admission to the emergency room of the HCB. Attendance of this clinic is intense in Bangui where there are few well-equipped hospitals where laboratory testing is possible. Criteria for enrollment in the study - in addition to age - were clinical symptoms evoking malaria (fever comprised between 37.5 and $39.5^{\circ} \mathrm{C}$ - axillary temperature; polyarthralgia; bilious vomiting; cephalalgia; dark urine). A summary of the survey is presented in Table I.

Enrollment was achieved when malaria diagnosis was ascertained by the presence of haemo-parasites seen on thick smears, and Plasmodium falciparum was then secondarily identified and > 600 infected erythrocytes $/ \mathrm{mm}^{3}$. Parasitaemia at admission ranged from 640 to 4,800 infected erythrocytes $/ \mathrm{mm}^{3}$ as calculated vs the leukocyte count (Table I).

Number of patients eligible for the survey

(May $15^{\text {th }}-$ June $30^{\text {th }} 2001$ )

Males, n (\%)

Females, n (\%)

Mean Age (extremes)

Mean axillary temperature (extremes)

Mean parasite density per $\mathrm{mm}^{3}$ (extremes)

Table I. - Summary of the patients included in the survey.

Upon admission to the clinics, one of the following treatments was randomly assigned to the patients in order to constitute three groups:

- A) Artecom $^{\circledR}: 32 \mathrm{mg}$ dihydroartemisin; $320 \mathrm{mg}$ piperaquine; $90 \mathrm{mg}$ trimethoprim given every $8 \mathrm{~h}$ for one day - three doses in total - (Tonghe Pharmaceutical CO Ltd, Yuzhong Chongging, People's Republic of China and Aspharca, CRA).

- B) sulfadoxin-pyrimethamin: $500 \mathrm{mg}$ sulfadoxin and $25 \mathrm{mg}$ pyrimethamin for a one-day treatment (IDA, The Netherlands).
- C) quinine: $500 \mathrm{mg}$ per day, for five consecutive days (IDA, The Netherlands). Assignment to protocol A, B, or $\mathrm{C}$ was made on the basis of every arrival to the hospital. Randomization consisted of assignment of the one treatment every other three eligible patients and so on. Patients gave informed consent to enter a random therapeutic protocol (with no placebo branch). Of note, the present protocol was approved solely by the ad hoc Committee of the hospital, in the absence of a national Ethic Committee in the CRA. The forthcoming protocols will be presented for ethical approval both in the CRA and in France.

The first dose of each treatment was taken by the patient, under supervision, in the clinics. After one hour resting - and in the absence of vomiting - patients included in the multi-drug intake (the quinine and the Artecom ${ }^{\circledR}$ branches) were provided with instructions for the rest of the treatment and were given the necessary tablets. In case of vomiting, a second dose of the initial treatment was given.

Visits to the clinics were planned at day 1, 2, 3, 7 and 14; and blood smears were scheduled on days 3, 7 and 14. Axillary temperature and general symptoms were monitored at each visit.

The protocol specified that the completion of treatment was needed even if the parasitaemia was cleared on day 1.

Of important note, the survey could not be completed for every patient because of the 2001 military insurrection that affected the possibility of some patients complying with the initial survey schedule.

\section{RESULTS}

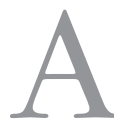

fter $P$. falciparum-malaria diagnosis confirmation and subsequent enrollment in the survey, 300 patients were eligible for this study, and actually 165 consecutive patients were enrolled; 54 patients received Artecom ${ }^{\circledR}, 80$ received sulfadoxinpyrimethamin and 31 received quinine orally. Differences within group constitution in numbers relies in the fact that more individuals enrolled in the Artecom ${ }^{\circledR}$ and quinine groups were secondarily excluded from the survey because they did not fulfill the requirements i.e.: i) proven and single Plasmodium falciparum (vs other species such as malariae or ovale) malaria and uncomplicated malaria; ii) and foremost compliance to the treatment as the treatment length was not identical (sulfadoxin-pyrimethamin: one day; $\operatorname{Artecom}^{\circledR}$ : one day; and quinine: five days).

The follow-up of patients was monitored as described. It appeared stringent that compliance with treatment was not good in this population; this provided, per se, interesting information. Criteria for drug efficacy 
(recovery) were: body temperature at day $1 \leq 37.5^{\circ} \mathrm{C}$ ); disappearance of symptoms by day 1 ; persistence of an asymptomatic status on days 2 and 3; substantial decrease of parasitaemia.

Criteria for drug inefficacy were the persistence or reappearance of clinical symptoms at day 2 ; persistence of parasitaemia. The outcome of parasitaemia in response to treatment is presented in Table II. As can further be seen in Table III, $\operatorname{Artecom}^{\circledR}$, sulfadoxinpyrimethamin and quinine induced, respectively: (i) about $95 \%, 60 \%$ and $65 \%$ parasitaemia reduction score (Table III-A); (ii) fever reduction by day 1 in $94.5 \%, 86.2 \%$ and 80,6\% (Table III-B); (iii) $75 \%$, $44.4 \%$ and $57 \%$ recovery in patients (Table III-C).
Artecom $^{\circledR}$ thus proved more efficient than the other two drugs in treating symptomatic, but uncomplicated, malaria in adults living in Bangui $\left(\chi^{2}=16.93\right.$; $\left.\mathrm{p}<0.05\right)$. Patients who were not cured by sulfadoxinpyrimethamin $(55.6 \%)$ and quinine $(42.8 \%)$ were then systematically given Artecom ${ }^{\circledR}$ orally on day 2 . Efficacy of Artecom ${ }^{\circledR}$ was then monitored on day 3 and proved efficient in all cases with parasitaemia counts dropping from $>100-3,600 / \mathrm{mm}^{3}$ (sulfadoxin-pyrimethamin) and $>360-460 / \mathrm{mm}^{3}$ (quinine) to $0-100 / \mathrm{mm}^{3}$. Of note, secondary relapses were treated with quinine IV. Artecom $^{\circledR}$ thus appears efficient in first (95\%) or second attempts (100\%) to treat symptomatic, uncomplicated malaria in adults living in Bangui.

\begin{tabular}{|c|c|c|c|}
\hline & Group 1 & Group 2 & Group 3 \\
\hline First line treatment (one day) & Artecom $^{\circledR}$ & Sulfadoxin-pyrimehamin (generic) & Quinine (generic) \\
\hline \# of individuals being assigned treatment & 67 & 101 & 42 \\
\hline \# of exclusions & 13 & 21 & 11 \\
\hline \# of patients enrolled in the survey & 54 & 80 & 31 \\
\hline Parasitaemia range at admission $(/ \mathrm{mm} 3)$ & $800-4,800$ & $815-4,200$ & $640-7,800$ \\
\hline Parasitaemia after one day treatment & $0-100$ & $300-3,000$ & $320-460$ \\
\hline Second line treatment & - & Artecom $^{\circledR}$ & Artecom $^{\circledR}$ \\
\hline Parasitaemia after second line treatment & - & $0-100$ & $0-100$ \\
\hline Efficacy & $\mathrm{p}<0.05$ & - & - \\
\hline
\end{tabular}

Table II. - Summary of the trial and follow up (efficacy comparison between anti-malarial drugs in Africans presenting with mild malaria in Bangui, CRA)

\begin{tabular}{|c|c|c|c|}
\hline $\begin{array}{l}\text { Patients groups } \\
\text { Drug used }\end{array}$ & $\begin{array}{l}1 \\
\text { Artecom }\end{array}$ & $\begin{array}{l}2 \\
\text { Sulfadoxin-pyrimethamin }\end{array}$ & $\begin{array}{l}3 \\
\text { Quinine }\end{array}$ \\
\hline $\begin{array}{l}\text { \# of individuals } \\
\text { in each group }\end{array}$ & 54 & 80 & 31 \\
\hline \multicolumn{4}{|c|}{ A - Parasitological response: \% reduction of parasitaemia (\# of patients having cleared parasites as detectable on blood smears; (\%)) } \\
\hline d0 & 0 & 0 & 0 \\
\hline d 3 & $12(22.2 \%)$ & $9(11.2 \%)$ & $12(38.7 \%)$ \\
\hline d 7 & $46(85.2 \%)$ & $41(51.2 \%)$ & $20(64.5 \%)$ \\
\hline d 14 & $51(94.5 \%)$ & $47(58.7 \%)$ & $20(64.5 \%)$ \\
\hline \multicolumn{4}{|c|}{ B - Clinical response: (a) fever: \# of apyretic patients in each group } \\
\hline d 0 & 0 & 0 & 0 \\
\hline d 3 & $51(94.5 \%)$ & $69(86.2 \%)$ & $12(80.6 \%)$ \\
\hline d 7 & $54(100 \%)$ & $80(100 \%)$ & $31(100 \%)$ \\
\hline d 14 & $54(100 \%)$ & $80(100 \%)$ & $31(100 \%)$ \\
\hline \multicolumn{4}{|c|}{ C - Clinical response : (b) no symptom of precocious therapeutic failure* (d1-d3) or no symptom of late therapeutic failure ${ }^{* * *}$ (d14) } \\
\hline d 0 & 0 & 0 & 0 \\
\hline d 3 & $39(72.22 \%)$ & $33(41.2 \%)$ & $17(54.8 \%)$ \\
\hline d 7 & $41(75.9 \%)$ & $33(41.2 \%)$ & $17(54.8 \%)$ \\
\hline d 14 & $41(75.9 \%)$ & $36(45 \%)$ & $18(58 \%)$ \\
\hline
\end{tabular}

Notes: * (no symptom of precocious therapeutic failure) stands for the absence of symptom evoking complication at d1-d3 (presence of parasitaemia at $\mathrm{d} 3$, augmentation of parasitaemia at $\mathrm{d} 3$ s $\mathrm{d} 0$, parasitaemia with axillary temperature $>37.5^{\circ} \mathrm{C}$ at $\mathrm{d} 3$ ); $* *$ ( no symptom of late therapeutic failure) stands for the presence of axillary temperature $>37.5^{\circ} \mathrm{C}$ between $\mathrm{d} 4$ and $\mathrm{d} 14$, or symptoms evoking complication after $\mathrm{d} 3$.

Table III. - Evolution of clinical and parasitological symptoms in each group of patients included in the comparative efficacy trial. 


\section{DISCUSSION}

T The present study consisted of an efficacy trial of three anti-malarial drugs or drug associations: it not only compared the initial parasite clearance time but also several clinical and biological parameters overtime. Obviously, however, there was a substantial discrepancy between all three groups having been constituted for the trial. We propose two reasons: (1) one protocol consisted in a one-dose treatment for which compliance was obviously excellent, while the other two protocols consisted of multidose drugs and certain individuals did not comply with the protocol; (2) by the end of the inclusion period, severe political trouble occurred in the CRA and especially in Bangui, preventing patients from complying with the visit schedule: several patients disappeared (not attending visits on days 1, 3, 7 and 14). However, the sample size was suitable with WHO requirements for drug efficacy trials: for example - if $P$ stands for the estimated failure index for a given drug in a given country, with a confidence interval of $95 \%$ and a variable precision degree referred to as $d$ (WHO, 1996) $-P_{\text {Artecom }}=0.15$ and $d_{\text {Artecom }}=0.1$, then the number of cases necessary for a survey $\left(N_{\text {Artecom }}\right)$ is 49 as read on the WHO abaque ( $N_{\text {sulfadoxin-pyrimethamin }}$ is 81 , and $N_{\text {quinin }}$ is 35). Thus, despite a number of missing patients and non-completion of enrollment in the present survey, the number of patients in each group is suitable for an efficacy comparison between drugs according to WHO.

This study confirms the extent of drug resistance to $P$. falciparum, especially to sulfadoxin-pyrimethamin and - to a lesser extent - to quinine as a consequence of gene mutation, antigen variability and allelic variation, caused by drug memory pressure and/or inappropriate drug use, which is not uncommon in febrile episodes in malaria endemic countries and especially in Africa (WHO, 1996). However, uncomplicated malaria can still be commonly treated orally and the use of Artecom ${ }^{\circledR}$ has substantially improved the outcome of uncomplicated $P$. falciparum infections in the CRA. It is not clear whether quinine given orally must still be used in a first attempt with Artecom ${ }^{\circledR}$ being given in cases of relapses (Adjuik et al., 2004), because this protocol would lead to $100 \%$ recovery compared to $75 \%$ in case of Artecom ${ }^{\circledR}$ first and also because quinine is considerably cheaper than Artecom $^{\circledR}$ (1 US \$ vs 3.32 US \$; sulfadoxin-pyrimethamin costs 2 US \$ in the CRA). As Artecom ${ }^{\circledR}$ fails to cure $25 \%$ of adult individuals presenting with mild malaria in Bangui, it remains to evaluate whether the systematic use in a first attempt of a protocol based on a combination of Artecom $^{\circledR}$ and quinine, which would be expected to lead to complete clearance of parasite in such a pop- ulation of semi-immune individuals (our ongoing survey), as there is indication that drug use interferes with naturally acquired immunity (French et al., 2001). As it is well known that artemisin-containing drugs lead to rapid reduction in initial parasite burden (Kyle et al., 1998), it would have been useful to continue the follow-up until day 7 or 14 without re-treatment to ensure the absence of relapse, which is planned in a forthcoming study. It also remains to evaluate the actual best strategy to cure younger individuals who cannot be considered semi-immune and pregnant women who consistently lose any protective immunity to $P$. falciparum.

Despite the fact that such studies seem relatively easy to perform in theory, drug accessibility in countries such as the RCA is severely impaired by one of the poorest economics in the world and by occasional political constraints, while the population is heavily exposed not only to $P$. falciparum (and other ssp.) malaria but also severe concurrent infection (such as tuberculosis, HIV/AIDS, etc.) which - each - may affect natural and/or specific immunity to each other, rendering therapeutic and/or prophylactic vaccines absolutely necessary.

\section{ACKNOWLEDGEMENTS}

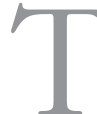
The authors would express their gratitude to Mr Yan (Aspahrca, Bangui, RCA); Dr J. Ngaba, Ministry of Health, Bangui, CRA; Dr Colonel M. Poukara, Director, Hôpital Communautaire de Bangui, RCA; Pr R. Tran Mahn Sung, Parasitology, University Hospital, Saint-Étienne, for support; and Mr Philip Lawrence for assistance in editing this manuscript.

\section{REFERENCES}

Adjuik M., Babiker A., Garner P., Olliaro P., Taylor W. \& White N. Artesunate combinations for treatment of malaria: meta-analysis. Lancet, 2004, 363, 9-17.

Bentwich Z., Maartens G., Torten D., Lal A.A. \& Lal R.B. Concurrent infections and HIV pathogenesis. Aids, 2000, 14, 2071-2081

Djimde A.A., Doumbo O.K., Traore O., Guindo A.B., Kayentao K., Diourte Y., Niare-Doumbo S., Coulibaly D., Kone A.K., Cissoko Y., Tekete M., Fofana B., Dicko A., Diallo D.A., Wellems T.E., Kwiatkowski D. \& Plowe C.V. Clearance of drug-resistant parasites as a model for protective immunity in Plasmodium falciparum malaria. American Journal of Tropical Medicine and Hygiene, 2003, 69, 558-563.

French N., NAKiyingi J., Lugada E., Watera C., Whitworth J.A. \& GiLks C.F. Increasing rates of malarial fever with deteriorating immune status in HIV-1-infected Ugandan adults. Aids, 2001, 15, 899-906. 
Kyle D.E., Teja-Isavadharm P., Li Q. \& Leo K. Pharmacokinetics and pharmacodynamics of qinghaosu derivatives: how do they impact on the choice of drug and the dosage regimens? Médecine Tropicale, 1998, 58, 38-44.

Tran T.H., Dolecek C., Pham P.M., Nguyen T.D., Nguyen T.T., Le H.T., Dong T.H., Tran T.T., Stepniewska K., White N.J. \& FARRAR J. Dihydroartemisinin-piperaquine against multidrug-resistant Plasmodium falciparum malaria in Vietnam: randomised clinical trial. Lancet, 2004, 363, 1822

White N.J. \& Olliaro P. Artemisinin and derivatives in the treatment of uncomplicated malaria. Médecine Tropicale, 1998, 58, 54-56.

WHO. Antimalarial drug combination therapy: report of a WHO technical consultation. Geneva: World Health Organization, 2001, WHO/CDS/RMB/2001.2035.

WHO. Assessement of therapeutic efficacy of antimalarial drugs for uncomplicated falciparum malaria in areas with intense transmission. Geneva: World Health Organization, 1996, WHO/MAL/1996.1077.

Reçu le 17 mai 2004

Accepté le 11 novembre 2004 